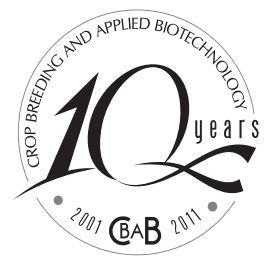

\title{
Effect of rootstock on the scion of Hevea brasiliensis through metabolic analysis of latex samples by ${ }^{1} \mathrm{H}$ NMR
}

Eduardo Sanches Pereira do Nascimento ${ }^{1 *}$, Clayton Rodrigues de Oliveira ${ }^{1}$, Paulo de Souza Gonçalves ${ }^{2}$, Reginaldo Brito da Costa ${ }^{3}$, Rogério Manoel Biagi Moreno ${ }^{4}$, Luiz Henrique Capparelli Mattoso ${ }^{4}$ and Antonio Gilberto Ferreira ${ }^{1 *}$

Received 4 April 2011

Accepted 22 June 2011

\begin{abstract}
In this study, the effect of rootstock on grafting through metabolomic analysis of latex (Hevea brasiliensis) samples was verified by ${ }^{1} H$ nuclear magnetic resonance (NMR) and multivariate data analysis. Sixteen metabolites present in the latex cytosol were characterized by NMR. PCA analysis showed that the latex samples of the RR and GR groups can be differentiated. The $G R$ group samples present a metabolic profile similar to the RR group samples, while the $R G$ group is in an intermediate position between RR and GG groups. Sucrose and formate contributed greatly to the separation obtained by PCA, presenting a good correlation between the results. ${ }^{1} \mathrm{H} N \mathrm{~N} R$ was an efficient technique to differentiate latex samples from different types of rootstocks and grafting and in the future could be used to predict rubber production by latex analysis.
\end{abstract}

Key words: metabolic profile, plant metabolomics, chemometric analysis, nuclearmagnetic resonance.

\section{INTRODUCTION}

Latex can be defined as a stable colloidal dispersion of a polymeric substance (rubber particles) in an essentially aqueous medium. Other minor compounds are present in latex composition such as proteins, carbohydrates, lipids, mineral salts, etc. Latex shows a distinct concentration in its chemical composition that depends of a lot of factors such as cultivation, soil, fertilizer and extraction procedure. Due to its intrinsic structure, latex possesses unique properties, being used in several industrial processes (Rippel and Bragança 2009).

Natural latex is extracted from Hevea brasiliensis, a tree also known as seringueira. Among the 11 Hevea existing species, the brasiliensis is the most outstanding, presenting the highest latex yield and genetic variability for disease resistance (Rippel and Bragança 2009). Due to its great vegetative and productive variability, seringueira seeds are used only for rootstock formation in nurseries and not for field plantations. Thus, plant propagation is preferentially made by grafting, using well defined clones, such as PB 235, RRIM 600 and GT 1. Grafting does not guarantee that the graft of a monoclonal block will be isogenic; in most rubber trees such expected uniformity by vegetative propagation does not occur (Cardinal et al. 2007).

Metabolomic analysis is defined as the identification and quantification of all metabolites in a biological system. In practice, most metabolomic studies are restricted to the use of analytical techniques capable of providing a general

\footnotetext{
${ }^{1}$ Universidade Federal de São Carlos (UFSCar), Departamento de Química, Campus São Carlos, 13.565-905, São Carlos, SP, Brazil; *Email: giba_04@yahoo.com.br

${ }^{2}$ Instituto Agronômico Campinas (IAC), Programa Seringueira, 13020-970, Campinas, SP, Brazil

${ }^{3}$ Universidade Federal de Mato Grosso (UFMT), Faculdade de Engenharia Florestal, Campus Cuiabá, 78.060-900, Cuiabá, MT, Brazil

${ }^{4}$ Empresa Brasileira de Pesquisa Agropecuária, 13560-970, São Carlos, SP, Brazil
} 
Effect of rootstock on the scion of Hevea brasiliensis through metabolomic analysis of latex samples by ${ }^{1} \mathrm{H}$ NMR

view of the metabolites, thus producing a metabolic fingerprinting of the system. Plant metabolomics is defined as the application of this concept to a specific system, a plant cultivated under defined conditions. In this case, the objective is to provide a broad view of the metabolic state of the plant, and show how the variation of this metabolic pattern affects the system under study (Weckwerth 2003, Schripsema 2010).

Several detection techniques have been used for metabolomic analysis, with the most outstanding being mass spectrometry (MS) and nuclear magnetic resonance (NMR) (Jonsson et al. 2004, Dunn et al. 2005). These techniques can be used directly or hyphenated to separation systems, such as liquid or gas chromatography. The main advantage of MS is its high sensitivity and capacity to detect hundreds of metabolites in a single run. NMR stands out for its reproducibility, short analysis time and mainly, for its structural identification capacity.

NMR is based on the principle that nuclei of certain atoms, when placed in a magnetic field, are capable of absorbing electromagnetic radiation at a characteristic frequency depending upon the position of each nucleus in a molecule. This radiation is later emitted and detected, producing a resonance spectrum of the nuclei that were excited (Jacobsen 2007). The large amount of information in a ${ }^{1} \mathrm{H}$ NMR, i.e., dozens of compounds that can be detected and which, in turn, present hundreds of resonance frequencies, makes its analysis quite laborious. Often these spectra contain information not very well perceived through a simple visual inspection. Thus, the use of statistical computational programs has helped to obtain these results, with multivariate data analysis being a widely applied strategy (Taylor et al. 2002, Katajamaa and Oresic 2007).

The objective of this study was to evaluate the influence of rootstock on grafting through metabolomic analysis of latex samples (Hevea brasiliensis) by ${ }^{1} \mathrm{H}$ NMR combined with multivariate data analysis.

\section{MATERIALS AND METHODS}

\section{Experimental design for collection of the latex samples}

The samples were collected at the former Pindorama Experimental Station of the Agronomic Institute (IAC), known today as 'Polo Regional de Desenvolvimento Tecnológico dos Agronegócios do Centro-Norte da Agência Paulista de Tecnologia dos Agronegócios' (APTA), in Pindorama, São Paulo (Cardinal et al. 2007).
Two Hevea clones (viz.RRIM 600 and GT 1) and two Hevea rootstocks (viz. RRIM 600 and GT 1) were combined to give four combinations. The illegitimate seeds for the rooststoks were collected in the border of monoclonal blocks sizing at least 2.0 ha. The sections (clones) were collected from the budwood stock nursery in Pindorama. Thee seeds were germinated in pre-nursery and transferred to polybags. One year later, the rootstocks raised in the polybags were budgrafted with the two clonal materials (sections). Each of two rootstocks and two scions were built up four combinations (Table 1).

Table 1. Experimental design of the collected latex samples

\begin{tabular}{|c|c|c|c|c|c|}
\hline \multirow{3}{*}{$\begin{array}{l}\text { Samples } \\
\text { Code }\end{array}$} & \multicolumn{4}{|c|}{ Grafting } & \multirow{3}{*}{$\begin{array}{c}\text { Rootstock }^{\mathrm{a}} \\
\text { Code }\end{array}$} \\
\hline & \multicolumn{2}{|c|}{ Rootstock } & \multicolumn{2}{|c|}{ Grafting } & \\
\hline & RIMM 600 & GT $1^{\mathrm{c}}$ & RIMM $600^{b}$ & $\overline{\text { GT } 1^{\mathrm{c}}}$ & \\
\hline RR09 & $\mathrm{X}$ & - & $\mathrm{X}$ & - & - \\
\hline RR10 & $\mathrm{X}$ & - & $\mathrm{X}$ & - & - \\
\hline RR11 & $\mathrm{X}$ & - & $\mathrm{X}$ & - & CR03 \\
\hline RR12 & $\mathrm{X}$ & - & $\mathrm{X}$ & - & CR04 \\
\hline RG13 & $\mathrm{X}$ & - & - & $\mathrm{X}$ & CR01 \\
\hline RG14 & $\mathrm{X}$ & - & - & $X$ & CR02 \\
\hline RG15 & $\mathrm{X}$ & - & - & $\mathrm{X}$ & - \\
\hline RG16 & $\mathrm{X}$ & - & - & $\mathrm{X}$ & - \\
\hline GR17 & - & $\mathrm{X}$ & $\mathrm{X}$ & - & CG05 \\
\hline GR18 & - & $\mathrm{X}$ & $\mathrm{X}$ & - & - \\
\hline GR19 & - & $\mathrm{X}$ & $\mathrm{X}$ & - & - \\
\hline GR20 & - & $\mathrm{X}$ & $\mathrm{X}$ & - & - \\
\hline GG21 & - & $\mathrm{X}$ & - & $\mathrm{X}$ & - \\
\hline GG22 & - & $\mathrm{X}$ & - & $\mathrm{X}$ & CG06 \\
\hline GG23 & - & $\mathrm{X}$ & - & $X$ & CG07 \\
\hline GG24 & - & $\mathrm{X}$ & - & $\mathrm{X}$ & CG08 \\
\hline
\end{tabular}

${ }^{\text {a }}$ Rootstock latex samples were taken from the graft samples studied. ${ }^{b}$ RIMM 600 (Tijir 1 x PB 86). ${ }^{\text {c }}$ GT1 (primary clone). x: present; -: absent.

When the four scion-rootstock combinations were 20 year old, a total of 24 latex samples were collected and analyzed in this study. Eight tappings (two each one) were performed in the rootstocks (RRIM 600 and GT 1) of the combinations. The other sixteen samples collected consisted of eight samples of latex RRIM 600 scions (four RRIM 600 scions grafted on RRIM 600 rootstocks) and four RRIM 600 scions grafted on GT 1 rootstocks), and eight samples of latex GT 1 scions (four GT 1 scions grafted on RRIM 600 and four GT scion grafted on GT 1 rootstocks). The RR and GG group samples can be considered as controls since the rootstock and the graft belong to the same type of clone. Aiming to obtain homogenous samples, plantation border effects were eliminated. 


\section{Preparation of the latex samples}

The trees were tapped according to the $1 / 2 \mathrm{~S} \mathrm{~d} / 45 \mathrm{~d} / 7$, ET $2.5 \%, 8 / y$ system (half spiral cut, tapped twice a week), and stimulated with $2.5 \%$ Ethefon applied on the tapping panel.

The latex samples were prepared by adding $500 \mathrm{~mL}$ of $\mathrm{D}_{2} \mathrm{O}$ to a $500 \mathrm{mg}$ sample. The $\mathrm{D}_{2} \mathrm{O}$ solution was prepared by adding a known amount of the internal standard TMSP$\mathrm{d}_{4}$ [2,2,3,3-d4-(3-trimethylsilyl)-sodium propionate]. The samples were centrifuged for $10 \mathrm{~min}$ at $10,000 \mathrm{rpm}$ at room temperature. Centrifugation separates the sample into four well-defined fractions, as described in the literature (Cook and Sekhar 1955). The intermediary fraction corresponds to latex cytosol. For NMR analyses, $600 \mathrm{~mL}$ of the intermediary fraction was collected and transferred into a $5 \mathrm{~mm}$ NMR tube.

\section{NMR analyses}

NMR measurements were performed on a Bruker Avance III Nanobay 9.4 T (400.13 MHz for hydrogen frequency) spectrometer placed at the NMR Laboratory of the Chemistry Department - Universidade Federal de São Carlos. The determinations were made with a BBFO $5 \mathrm{~mm}$ probe (direct detection) with field gradient generating coils in the $\mathrm{z}$ coordinate.

All the spectra were acquired at $303 \mathrm{~K}$, using the presaturation pulse sequence NOESYGPPR1D to suppress the residual water signal. Sixty-four scans (ns) were accumulated, with a delay time between each acquisition of $4 \mathrm{~s}$ (d1), acquisition time of $3.98 \mathrm{~s} \mathrm{(aq)} \mathrm{with} 64 \mathrm{~Kb}$ points during acquisition (td), and presaturation pulse attenuation of $41.40 \mathrm{~dB}$ (pldb9). The mixture time used was $10 \mathrm{~ms}$ (d8) and $90^{\circ}$ pulse duration was $9.98 \mathrm{~ms}(\mathrm{p} 1)$. Spectra processing were carried out with $64 \mathrm{~Kb}$ points (si), using an exponential multiplication with $\mathrm{lb}=0.3 \mathrm{~Hz}$ and manual phase correction.

$\mathrm{Bi}$-dimensional $g \mathrm{COSY}$ and J-res spectra were obtained using the pulse sequences cosygpprqf and lcjrespr, spectral width (swh) in F1 8012 and 50, and td in F1 of 256 and 128, respectively. The following parameters were the same for the two measurements: $\mathrm{ns}=16, \mathrm{~d} 1=2 \mathrm{~s}$, td in F2 of $4 \mathrm{~Kb}$ and swh in F2 8012. Spectra processing were carried out with $4 \mathrm{~Kb}$ points in $\mathrm{F} 2$ and $1 \mathrm{~Kb}$ points in F1 (si).

\section{Multivariate analyses}

Multivariate data analyses were carried out using the software The Unscrambler ${ }^{\circledR}$ v. 9.7. At the preprocessing stage, all data were autoscaled. For matrix construction, the regions referring to the water, polyisoprene, and TMSP$\mathrm{d}_{4}$ signal were removed. The algorithm used in the multivariate analyses was PCA (Principal Component Analyses) (Beebe et al. 1998).

\section{RESULTS AND DISCUSSION}

\section{Metabolic profile}

A typical ${ }^{1} \mathrm{H}$ NMR spectrum of a latex sample is shown in Figure 1. The metabolites were assigned according to literature (Sobolev et al. 2005) and through the analyses of bi-dimensional spectra $g$ COSY and J-res (Figure 2). Table 2 lists the metabolites identified in the latex samples along with their respective chemical shifts.
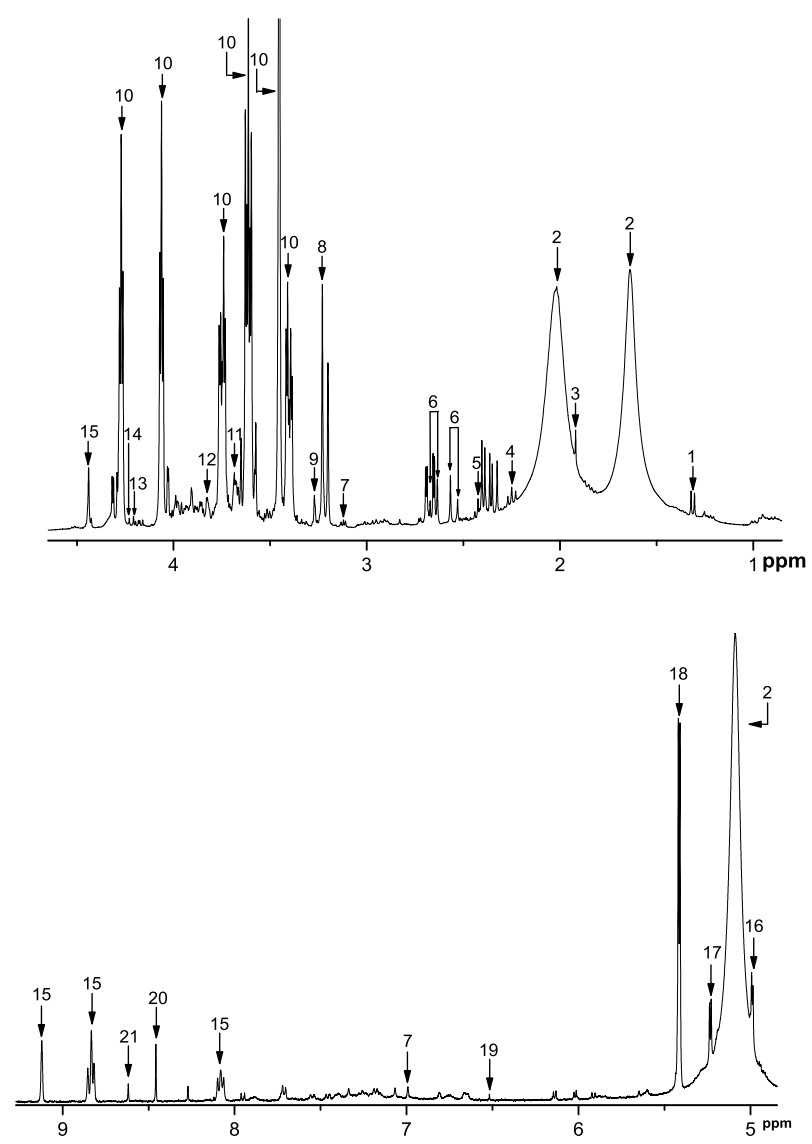

Figure 1. Typical ${ }^{1} \mathrm{H}$ NMR spectrum of a latex sample.

Sixteen metabolites were identified in the latex cytosol. As observed in Figure 1, the metabolite present in the highest amount (signals in the range of 3.0 to 4.0 ppm) is quebrachitol (2-O-methyl-l-inositol), a cyclic polyol 


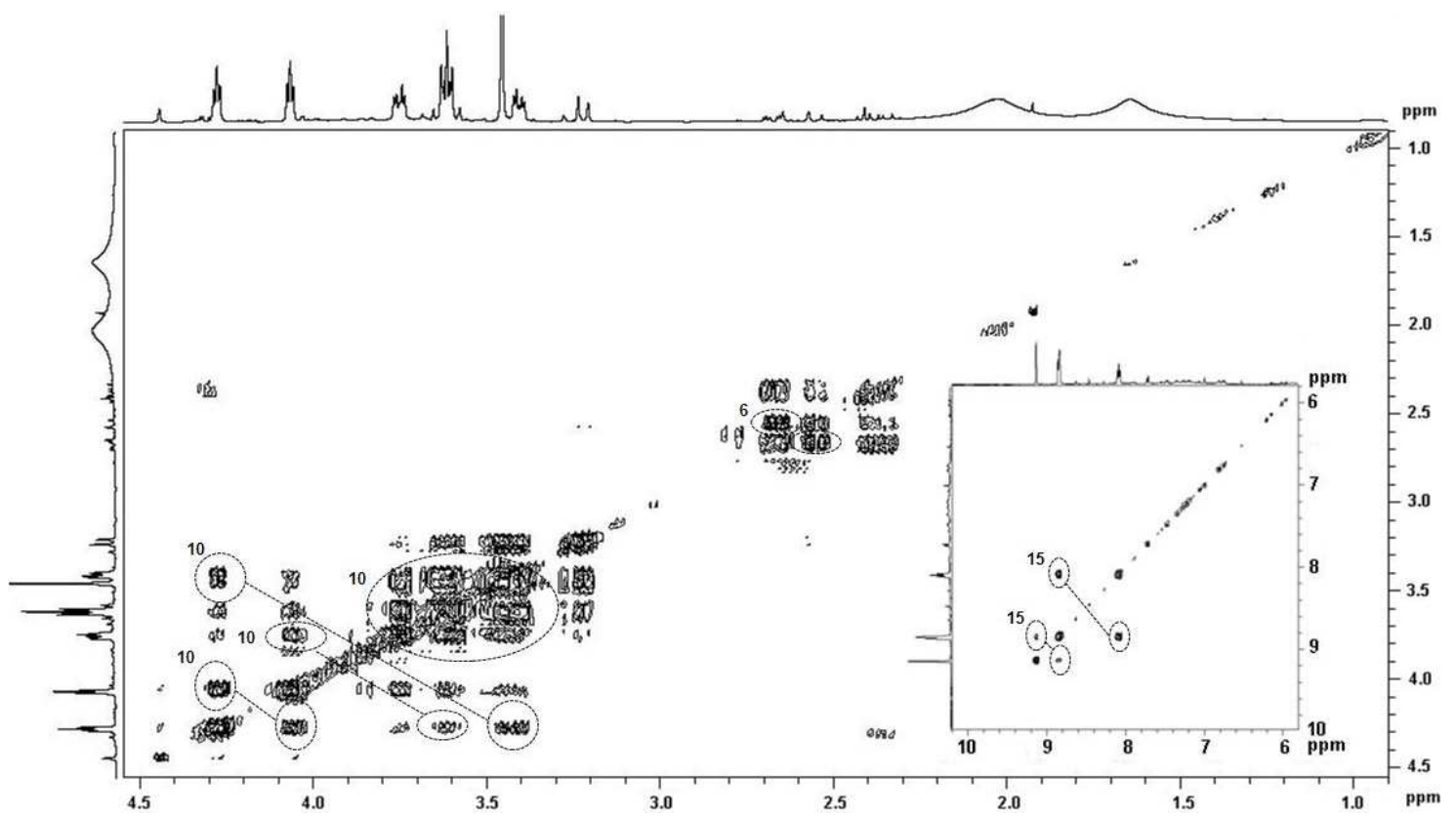

Figure 2. Typical $g$ COSY NMR spectrum of a latex sample.

stereoisomer of inositol. Quebrachitol is produced in the laticiferous cytoplasm, and its concentration in the latex is in the range of $1.2 \%(\mathrm{~m} / \mathrm{v})$. Its participation in latex synthesis is not completely known yet, however quebrachitol contributes significantly to the formation and maintenance of the laticiferous turgor pressure (Dusotoit-Coucaud 2010). The two broad signals in the region of 1.1 to 2.3 $\mathrm{ppm}$ and the signal at $5.1 \mathrm{ppm}$ are residual signals of polyisoprene that could not be completely removed during the centrifugation step. The region from 1.0 to $3.0 \mathrm{ppm}$ is characteristic of amino acids, however these signals could not be assigned due to the presence of the residual signals of polyisoprene.

Three nitrogenated compounds were identified. One of these is trigonelin with characteristic signals in the hetero aromatics region (8.0 to $9.2 \mathrm{ppm}$ ). Trigonelin is an $\mathrm{N}$-methyl betaine present in plants such as coffee, tomato and potato (Ky et al. 2001, Le Gall et al. 2003, Defernez et al. 2004). Its presence in latex samples has been reported (Shrestha and Bisset 1991), but its function is unknown. Other classes of compounds, such as organic acids and sugars, were also identified.

\section{Multivariate data analyses and quantification}

Multivariate data analyses allow the visualization of a variation pattern intrinsic to the dataset. This variation pattern cannot be verified just by comparing the spectra, due to a large number of signals originated from the metabolites present in the sample. An exploratory analysis of the data was performed using the PCA algorithm. PCA analyses allow visualization of groups formed by samples with the same metabolic profile. Figure 3 a presents the score plot of RR and GG latex samples. The sum of the values obtained for the first three principal components (PC1 (39\%), PC2 (19\%) and PC3 (14\%)) explained $72 \%$ of the total variation in the data set. As it can be seen, there is a strong tendency of clustering between samples of the group RR and group GG. The loading plot (Figure 3b) shows the spectra regions that most contributed, in the first principal component, for the separation obtained. According to Figure $3 b$, the metabolites that most contributed for the separation obtained were formate $(8.46 \mathrm{ppm})$, sucrose (5.41 ppm) and the signals of the metabolites 21 (8.62 ppm), 14 (4.23 ppm), 13 (4.21 ppm), 12 (3.83 ppm) and 11 (3.68 ppm), which were not identified.

To verify the influence of rootstock on grafting, a new PCA analysis was conducted considering groups RR, GG, RG and GR. Figure 3c presents the score plot of this analyses and the sum of the values obtained for the three principal components [PC1 (32\%), PC2 (20\%) and PC3 (11 $\%)$ ] explained $63 \%$ of the total variance in the data set. In Figure $3 \mathrm{c}$, the formation of groups for samples RR and GG was again observed, according to the previous analyses (Figure 3a). The RG group samples present a strong 
ESP Nascimento et al.

Table 2. Metabolites identified in the latex samples

\begin{tabular}{|c|c|c|}
\hline Code & Metabolite & $\delta{ }^{1} \mathbf{H}$ ppm (multiplicity, J Hz) \\
\hline \multirow[t]{2}{*}{1} & Lactate & $1.33(\mathrm{~d}, 6.78)$ \\
\hline & & $1.64(\mathrm{bs})$ \\
\hline \multirow[t]{2}{*}{2} & Polyisoprene & $2.02(\mathrm{bs})$ \\
\hline & & $5.09(\mathrm{bs})$ \\
\hline 3 & Acetate & $1.92(\mathrm{~s})$ \\
\hline 4 & Acetoacetate & $2.26(\mathrm{~s})$ \\
\hline 5 & Succinate & $2.42(\mathrm{~s})$ \\
\hline \multirow{2}{*}{6} & \multirow{2}{*}{ Citrate } & $2.55(\mathrm{~d}, 15.16)$ \\
\hline & & $2.65(\mathrm{~d}, 15.16)$ \\
\hline \multirow{2}{*}{7} & \multirow{2}{*}{ Aconitate } & $3.12(\mathrm{~s})$ \\
\hline & & $6.99(\mathrm{~s})$ \\
\hline 8 & Choline (8) & $3.23(\mathrm{~s})$ \\
\hline 9 & Betaine (9) & $3.27(\mathrm{~s})$ \\
\hline \multirow{6}{*}{10} & \multirow{6}{*}{ Quebrachitol } & $3.40(\mathrm{ddd})$ \\
\hline & & $3.45(\mathrm{~s})$ \\
\hline & & 3.61 (ddd) \\
\hline & & 3.74 (ddd) \\
\hline & & $4.06(\mathrm{dd})$ \\
\hline & & $4.27(\mathrm{dd})$ \\
\hline 11 & Unknown & 3.68 \\
\hline 12 & Unknown & 3.83 \\
\hline 13 & Unknown & 4.20 \\
\hline 14 & Unknown & 4.22 \\
\hline \multirow{4}{*}{15} & \multirow{4}{*}{ Trigonelline } & $4.44(\mathrm{~s})$ \\
\hline & & $8.08(\mathrm{t}, 7.00)$ \\
\hline & & $8.83(\mathrm{t}, 7.00)$ \\
\hline & & $9.12(\mathrm{~s})$ \\
\hline 16 & Raffinose & $4.99(\mathrm{~d}, 3.80)$ \\
\hline 17 & $\alpha$-Glucose & $5.24(\mathrm{~d}, 3.80)$ \\
\hline 18 & Sucrose & $5.41(\mathrm{~d}, 3.80)$ \\
\hline 19 & Fumarate & $6.52(\mathrm{~s})$ \\
\hline 20 & Formate & $8.46(\mathrm{~s})$ \\
\hline 21 & Unknown & 8.62 \\
\hline
\end{tabular}

S: singlet, bl: broad singlet, d: doublet, dd: double doublet, ddd: double double doublet, t: triplet.

tendency to cluster with the RR and GG groups, while the GR group samples cluster preferentially with the RR group samples. The loading plot for the RR, GG, RG and GR samples is presented in Figure 3d. The same signals responsible for the separation of the RR and GG samples are also found to have a strong influence on this separation.

To verify the variability of metabolites in the different latex samples, a relative quantification was carried out for sucrose and formate, important compounds for the separation of groups for PCA analysis, and quebrachitol (Table 3). The considerations done below are based only on the average values of the metabolites found for each group, since the number of samples is not sufficient to provide significant information through a univariate statistical analysis. In general, no significant variation was observed in the quebrachitol content among the grafting latex samples. This information is observed in the loading plots of the PCA analyses, as this metabolite had no influence on the separations obtained. The GG group samples presented higher amounts of sucrose and formate than the RR group samples. The difference in the concentration of these metabolites explains the good separation obtained in the PCA analyses. The GR group samples presented amounts of sucrose and formate similar to those of the RR group, indicating why these samples cluster in the PCA analyses (Figure 3c). The RG group samples presented intermediary sucrose and formate values, the reason why this group is between the RR and the GG group.

Rootstock samples CR01 and CR02 presented higher amounts of sucrose and lower amounts of quebrachitol, compared to the samples of the same group CR03 and CR04. This difference can be explained by the fact that the samples CR01 and CR02 were grafted with clone GT 1, whereas the samples CR03 and CR04 were grafted with RRIM 600, indicating a possible influence of grafting on rootstock. The rootstock samples CG06 and CG07 grafted with GT 1 presented higher amounts of sucrose, compared to sample CG05, grafted with RRIM600. In general, it was observed that the rootstock samples grafted with GT 1 presented higher sucrose amounts than those grafted with RRIM 600.

\section{CONCLUSIONS}

Nuclear magnetic resonance $\left({ }^{1} \mathrm{H}\right.$ NMR and bidimensional spectra) was an important tool for identification and relative quantification of the main metabolites in latex samples. ${ }^{1} \mathrm{H}$ NMR data, combined with multivariate analyses, allowed distinguishing among the latex samples in groups according to rootstock and grafting. Determination of relative amounts of sucrose and formate in the latex samples, along with identification of the unknown metabolites presented in this study, could help future correlation of metabolites in latex and rubber production through determination of their respective biochemical functions.

\section{ACKNOWLEDGEMENTS}

To Fundação de Amparo à Pesquisa do Estado de São Paulo (FAPESP), Conselho Nacional de Desenvolvimento Científico e Tecnológico (CNPq), and Coordenação de Aperfeiçoamento de Pessoal de Nível Superior (CAPES) for the financial support. 
Effect of rootstock on the scion of Hevea brasiliensis through metabolomic analysis of latex samples by ${ }^{1} \mathrm{H}$ NMR
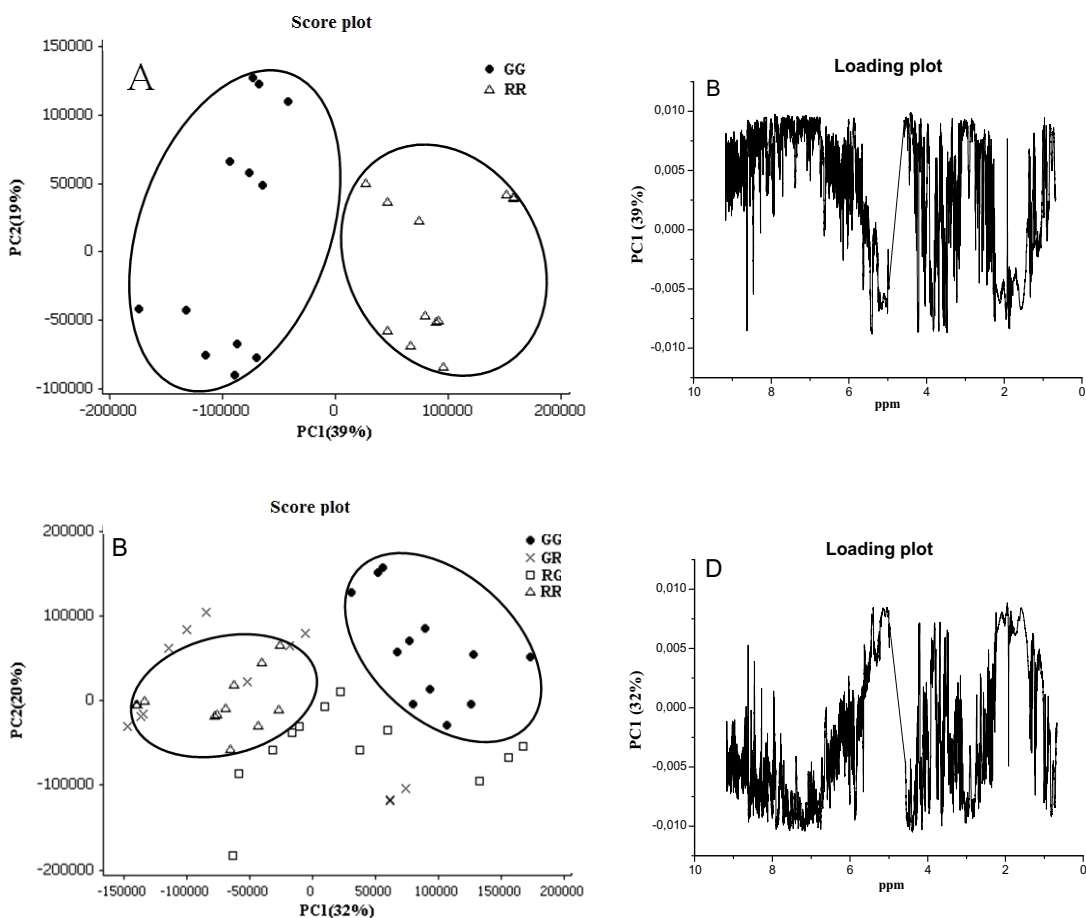

Figure 3. Results obtained from PCA analyses. A) Score plot of RR and GG groups B) Loading plot of RR and GG groups; C) Score plot of RR; GG, RG and GR groups; D) Loading plot of RR, GG, RG, and GR groups.

Table 3. Relative quantification (metabolite/TMSP-d4 area) of some metabolites that contributed for discrimination between the RR, GG, RG and GR groups

\begin{tabular}{|c|c|c|c|c|c|c|}
\hline Sample & Sucrose & Average & Formate & Average & Quebrachitol & Average \\
\hline CR01 & 0.149 & \multirow{4}{*}{0.0713} & 0.00275 & \multirow{4}{*}{0.00458} & 3.784 & \multirow{4}{*}{3.94} \\
\hline CR02 & 0.0880 & & 0.00519 & & 2.705 & \\
\hline CR03 & 0.0220 & & 0.00328 & & 4.400 & \\
\hline CR04 & 0.0260 & & 0.00710 & & 4.878 & \\
\hline CG05 & 0.0300 & \multirow{4}{*}{0.0923} & 0.00441 & \multirow{4}{*}{0.00595} & 4.776 & \multirow{4}{*}{4.57} \\
\hline CG06 & 0.2030 & & 0.00420 & & 4.739 & \\
\hline CG07 & 0.1060 & & 0.00535 & & 4.159 & \\
\hline CG08 & 0.0300 & & 0.00985 & & 4.591 & \\
\hline RR09 & 0.0190 & \multirow{4}{*}{0.0427} & 0.00266 & \multirow{4}{*}{0.00299} & 5.539 & \multirow{4}{*}{5.09} \\
\hline RR10 & 0.0590 & & 0.00478 & & 5.861 & \\
\hline RR11 & 0.0500 & & 0.00340 & & 4.461 & \\
\hline RR12 & ND & & 0.00111 & & 4.495 & \\
\hline RG13 & 0.0890 & \multirow{4}{*}{0.0645} & 0.00608 & \multirow{4}{*}{0.00722} & 3.735 & \multirow{4}{*}{3.57} \\
\hline RG14 & 0.0680 & & 0.01000 & & 2.875 & \\
\hline RG15 & 0.0340 & & 0.00459 & & 4.403 & \\
\hline RG16 & 0.0670 & & 0.00821 & & 3.273 & \\
\hline GR17 & 0.0440 & \multirow{4}{*}{0.0280} & 0.00254 & \multirow{4}{*}{0.00211} & 4.370 & \multirow{4}{*}{4.65} \\
\hline GR18 & 0.0230 & & 0.00176 & & 4.810 & \\
\hline GR19 & 0.0170 & & 0.00261 & & 4.427 & \\
\hline GR20 & ND & & 0.00152 & & 4.976 & \\
\hline GG21 & 0.2170 & \multirow{4}{*}{0.209} & 0.01170 & \multirow{4}{*}{0.00700} & 4.625 & \multirow{4}{*}{4.81} \\
\hline GG22 & 0.2770 & & 0.00675 & & 4.426 & \\
\hline GG23 & 0.1570 & & 0.00549 & & 4.629 & \\
\hline GG24 & 01840 & & 000404 & & 5554 & \\
\hline
\end{tabular}




\title{
Influência de porta-enxerto sobre enxerto através da análise metabolômica de amostras de látex de Hevea brasiliensis por RMN de ${ }^{1} \mathrm{H}$
}

\begin{abstract}
RESUMO - Nesse trabalho a influência do porta-enxerto sobre o enxerto nas amostras de látex (Hevea brasiliensis) foi verificada através da análise de $R M N$ de ${ }^{1} H$ e análise multivariada dos dados. Através da análise de RMN de ${ }^{1} H$ foi possível caracterizar 16 metabólitos presentes no citosol do látex. A análise de PCA mostrou que as amostras de látex dos grupos RR e GG podem ser diferenciadas. As amostras do grupo GR possuem perfil metabólico semelhante às amostras do grupo RR, enquanto o grupo RG situa-se em posição intermediária entre os grupos RR e GG. A sacarose e o formiato contribuíram em grande parte pela separação obtida por PCA e apresentaram boa correlação com os resultados obtidos. A RMN de ${ }^{l} H$ provou ser uma técnica eficiente na diferenciação entre amostras provenientes de diferentes tipos de porta-enxerto e enxerto e pode futuramente ser utilizada para prever a produção de borracha através da análise do látex.
\end{abstract}

Palavras-chave: perfil metabólico, metabolômica de plantas, análise quimiométrica, ressonância magnética nuclear.

\section{REFERENCES}

Beebe KR, Pell RJ and Seasholtz MB (1998) Chemometrics: a practical guide. John Wiley \& Sons, Nova Jersey, 348p.

Cardinal ABB, Gonçalves OS and Martins ALM (2007) Influência de seis porta-enxertos sobre a produção de clones superiores de seringueira. Bragantia 66: 277-284.

Cook AS and Sekhar BC (1955) Fractions from Hevea brasiliensis latex centrifuged at 59,000 g. Journal of The Rubber Research Institute of Malysia 14: 163.

Defernez M, Gunning YM, Parr AJ, Shepherd LVT, Davies HV and Colquhoun IJ (2004) NMR and HPLC-UV profiling of potatoes with genetic modifications to metabolic pathways. Journal of Agricultural and Food Chemistry 52: 6075-6085.

Dunn WB, Bailey NJC and Johnson HE (2005) Measuring the metaboloma: current analytical technologies. The Analyst 130: 606-625.

Dusotoit-Coucaud A, Porcheron B, Brunel N, Kongsawadworakul P, Franchel J, Viboonjun U, Chrestin H, Lemoine R and Sakr S (2010) Cloning and characterization of a new polyol transporter (HbPlT2) in Hevea brasiliensis. Plant \& Cell Physilogy 51: 1878-1888.

Jacobsen NE (2007) NMR spectroscopy explained: simplified theory, applications and examples for organic chemistry and structural biology. John Wiley \& Sons, Nova Jersey, $668 \mathrm{p}$.

Jonsson P, Gullberg J, Nordstrom A, Kusano M, Kowalczyc M, Sjostrom M and Moritz T (2004) A Strategy for Identifying Differences in Large Series of Metabolomic Samples Analyzed by GC/MS. Analytical Chemistry 76: 1738-1745.
Katajamaa M and Oresic M (2007) Data processing for mass spectrometry-based metabolomics. Journal of Chromatography A 1158: $318-328$.

Ky CL, Louarn J, Dussert S, Guyot B, Hamon S and Noirot M (2001) Caffeine, trigonelline, chlorogenic acids and sucrose diversity in wild Coffea arabica L. and C. canephora P. Food Chemistry 75: 223-230.

Le Gall G, Colquhoun IJ, Davis AL, Collins GJ and Verhoeyen ME (2003) Metabolite profiling of tomato (Lycopersicon esculentum) using H-1 NMR spectroscopy as a tool to detect potential unintended effects following a genetic modification. Journal of Agricultural and Food Chemistry 51: 24472456 .

Rippel MM and Bragança FC (2009) Borracha natural e nanocompósitos com argila. Química Nova 32: 818-826.

Schripsema J (2010) Application of NMR in plant metabolomics: techniques, problems and prospects. Phytochemical Analysis 21: $14-21$

Shrestha T and Bisset NG (1991) Quaternary nitrogen-compounds from south-american moraceae. Phytochemistry 30: 32853287 .

Sobolev AP, Brosio E, Gianferri R and Segre AL (2005) Metabolic profile of lettuce leaves by high-field NMR spectra. Magnetic Resonance in Chemistry 43: 625-638.

Taylor J, King RD, Altmann T and Fiehn O (2002) Application of metabolomics to plant genotype discrimination using statistics and machine learning. Bioinformatics 18: S241-S248.

Weckwerth W (2003) Metabolomics in systems biology. Annual Review of Plant Biology 54: 669-689. 